\title{
Peripheral brain-derived neurotrophic factor is related to cardiovascular risk factors in active and inactive elderly men
}

\author{
A. Zembron-Lacny ${ }^{1}$, W. Dziubek ${ }^{2}$, M. Rynkiewicz ${ }^{3}$, B. Morawin ${ }^{3}$ and M. Woźniewski ${ }^{2}$ \\ ${ }^{1}$ Department of Applied and Clinical Physiology, Faculty of Medicine and Health Sciences, University of Zielona Gora, \\ Zielona Gora, Poland \\ ${ }^{2}$ Department of Physiotherapy in Internal Diseases, Faculty of Physiotherapy, University School of Physical Education in Wroclaw, \\ Wroclaw, Poland \\ ${ }^{3}$ Department of Biological Basis of Sport, Faculty of Medicine and Health Sciences, University of Zielona Gora \\ Zielona Gora, Poland
}

\begin{abstract}
Regular exercise plays an important preventive and therapeutic role in heart and vascular diseases, and beneficially affects brain function. In blood, the effects of exercise appear to be very complex and could include protection of vascular endothelial cells via neurotrophic factors and decreased oxidative stress. The purpose of this study was to identify the age-related changes in peripheral brain-derived neurotrophic factor (BDNF) and its relationship to oxidative damage and conventional cardiovascular disease (CVD) biomarkers, such as atherogenic index, C-reactive protein (hsCRP) and oxidized LDL (oxLDL), in active and inactive men. Seventeen elderly males (61-80 years) and 17 young males (20-24 years) participated in this study. According to the 6-min Åstrand-Rhyming bike test, the subjects were classified into active and inactive groups. The young and elderly active men had a significantly better lipoprotein profile and antioxidant status, as well as reduced oxidative damage and inflammatory state. The active young and elderly men had significantly higher plasma BDNF levels compared to their inactive peers. BDNF was correlated with $\mathrm{VO}_{2} \max (\mathrm{r}=0.765, \mathrm{P}<0.001)$. In addition, we observed a significant inverse correlation of $\mathrm{BDNF}$ with atherogenic index (TC/HDL), hsCRP and oxLDL. The findings demonstrate that a high level of cardiorespiratory fitness reflected in $\mathrm{VO}_{2}$ max was associated with a higher level of circulating BDNF, which in turn was related to common CVD risk factors and oxidative damage markers in young and elderly men.
\end{abstract}

Key words: Neurotrophins; Lipoproteins; Oxidative damage; Aging; Cardiorespiratory fitness

\section{Introduction}

Regular exercise is known to improve the physiological performance of skeletal and cardiac muscles and decrease the incidence of a wide range of diseases, including heart and vascular diseases, certain kinds of cancers, type 2 diabetes, etc. (1). In the last decade, it has become clear that regular exercise beneficially affects brain function as well, and could play an important preventive and therapeutic role in stroke and degenerative diseases $(2,3)$. The effects of exercise appear to be very complex and could include enhanced angiogenesis, neurogenesis and mitogenesis via neurotrophic factors, and reduced oxidative stress (4).

Brain-derived neurotrophic factor (BDNF) is a part of the neurotrophic family of growth factors, and is responsible for enhancing progenitor cell proliferation and differentiation, cell growth and regeneration processes, neuronal survival, and long-term synaptic remodeling and plasticity. The effects of neurotrophins are mediated by a family of specific transmembrane tyrosine kinase receptors, of which, TrkB is the primary signal transduction receptor for $\operatorname{BDNF}(5,6)$. BDNF has been identified as a key component of the hypothalamic pathway that controls body mass and energy homeostasis (3). Kermani et al. (7) and Matthews et al. (8) have shown that BDNF appears to be a major player not only in central metabolic pathways but also as a regulator of angiogenesis and muscle regeneration where it is responsible for mobilization of hematopoietic progenitor cells as well as proliferation and differentiation of satellite cells.

Studies have demonstrated that physical exercise can increase peripheral BDNF levels. In humans, BDNF release from the brain was observed at rest and increased 
even 3-fold during exercise. Both at rest and during exercise, the brain contributed to $70-80 \%$ of the circulating BDNF (9). This suggests that the brain is a major, but not the sole, contributor to peripheral BDNF. However, Matthews et al. (8) demonstrated that muscle-derived BDNF did not appear to be released into circulation. Interestingly, BDNF synthesis increased by muscle contraction enhances fat oxidation in an AMPK-dependent fashion, most probably by acting in an autocrine and/or paracrine manner within skeletal muscle. Hence, BDNF has been identified as a novel contraction-induced protein that may contribute to the multiple health benefits associated with physical activity (3).

It has been demonstrated that factors, such as age, race, gender, and weight, have an influence on stored and circulating BDNF levels in humans $(10,11)$. Coelho et al. (12) provided a review of six studies that examined the effect of exercise on BDNF in elderly individuals. They found that it was not possible to establish a recommendation protocol for the type and intensity of physical exercise required to produce an increase in BDNF levels. However, moderate-intensity exercises, such as walking, seem to be the most effective to promote an increase in peripheral levels of BDNF among the elderly (13). More recently, Huang et al. (14) reviewed 32 experimental studies and reported that peripheral BDNF concentrations were elevated by acute and chronic aerobic exercise. The majority of the studies demonstrated that strength training had no influence on peripheral BDNF.

There has been a growing body of research focusing on the relationship between physical activity and BDNF levels in peripheral blood. Three review articles in this area have been published. The first one presented a systematic review of experimental studies on the effects of exercise on peripheral BDNF in healthy subjects and persons with a disease or disability, including methodological issues (15). The results from a few experimental studies showed contrary relationships between the peripheral BDNF level and habitual physical activity or cardiorespiratory fitness (16-19). Therefore, the purpose of this study was to identify the age-related changes in peripheral BDNF and its relationship to oxidative damage and conventional health markers in active and inactive men.

\section{Material and Methods}

Thirty elderly men were recruited from the University of the Third Age U3T (age 60-80 years) who did not declare sport experience ten years after retirement. The current health status and lifestyle of the subjects were recorded using the health history questionnaire $(20,21)$. Exclusion criteria, based on the assessment of the responsible physician and investigator, were acute infectious diseases, cardiovascular, neurological and musculoskeletal disturbances as well as blood transfusion. Twenty-three left the study because of high dyslipidemia, hypertension, dementia and intake of some medications, e.g., antidepressants, beta-adrenergic blocking agents and nonsteroidal anti-inflammatory drugs. Seventeen healthy untrained males, ages 20-24 years, composed a reference group (Table 1).

All subjects were informed of the aim of the study and gave their written consent for participation in the project. The Bioethics Commission at Medical University Poznan ( $N^{\circ} 392 / 13$ ), in accordance with the Helsinki Declaration, approved the protocol of the study.

\section{Body composition}

Body mass and body composition (fat-free mass, FFM, and fat mass, FM) were estimated by a bioelectrical impedance method using Tanita body composition

Table 1. Subject characteristics.

\begin{tabular}{lccccc}
\hline & \multicolumn{2}{c}{ Young } & & \multicolumn{2}{c}{ Elderly } \\
\cline { 2 - 3 } \cline { 6 - 6 } & Active $(\mathrm{n}=6)$ & Inactive $(\mathrm{n}=11)$ & & Active $(\mathrm{n}=5)$ & Inactive $(\mathrm{n}=12)$ \\
\hline Age (years) & $21.7 \pm 1.9$ & $21.0 \pm 1.1$ & & $71.2 \pm 5.1^{\#}$ & $71.1 \pm 5.3^{\&}$ \\
Height $(\mathrm{cm})$ & $184.8 \pm 6.7$ & $178.5 \pm 6.9$ & & $166.5 \pm 8.9^{\#}$ & $169.3 \pm 5.3$ \\
Weight $(\mathrm{kg})$ & $74.8 \pm 9.6$ & $74.5 \pm 4.8$ & & $75.7 \pm 16.2$ & $74.2 \pm 8.0$ \\
BMl $\left(\mathrm{kg} / \mathrm{m}^{2}\right)$ & $21.9 \pm 2.8$ & $23.4 \pm 1.9$ & & $27.1 \pm 4.5$ & $25.9 \pm 2.8$ \\
FFM $(\mathrm{kg})$ & $60.3 \pm 6.2$ & $60.4 \pm 4.6$ & & $51.7 \pm 9.5$ & $51.6 \pm 6.4^{\&}$ \\
FM $(\mathrm{kg})$ & $14.6 \pm 4.0$ & $14.1 \pm 2.2$ & & $24.0 \pm 7.3^{\#}$ & $22.6 \pm 4.7^{\&}$ \\
\%FM & $19.2 \pm 3.5$ & $19.0 \pm 2.8$ & & $31.2 \pm 4.2^{\#}$ & $30.5 \pm 5.3^{\&}$ \\
SBP $(\mathrm{mmHg})$ & $141 \pm 12$ & $151 \pm 7$ & & $161 \pm 30$ & $153 \pm 23$ \\
DBP $(\mathrm{mmHg})$ & $77 \pm 5$ & $82 \pm 8$ & & $88 \pm 7$ & $87 \pm 13$ \\
VO ${ }_{2} \mathrm{max}\left(\mathrm{mL} \cdot \mathrm{kg}^{-1} \cdot \mathrm{min}^{-1}\right)$ & $60.9 \pm 6.4$ & $42.0 \pm 6.8^{\#}$ & & $43.4 \pm 5.9^{\#}$ & $30.0 \pm 6.0^{\star \&}$ \\
\hline
\end{tabular}

Data are reported as means \pm SD. BMI: body mass index; FFM: fat-free mass; FM: fat mass; SBP: systolic blood pressure; DBP: diastolic blood pressure; $\mathrm{VO}_{2}$ max: maximal oxygen consumption. \#P $<0.05$ vs young active; ${ }^{*} \mathrm{P}<0.05$ vs elderly active; ${ }^{\circledR} \mathrm{P}<0.05$ vs young inactive (ANOVA). 
analyzer BC-418MA (Japan) calibrated prior to each test session in accordance with the manufacturer's guidelines. Duplicate measurements were taken with the participant in a standing position; the average value was used for the final analysis. The recurrence of measurement was $98 \%$. The measurements were taken between 7:00 and 8:00 am, before blood sampling.

\section{Cardio-respiratory fitness}

Maximal oxygen consumption $\left(\mathrm{VO}_{2} \max \right)$ was measured via the indirect method known as the AstrandRhyming bike test (6-min submaximal exercise test) recommended for both men and women of various ages which relies on the linear relationship between heart rate and $\mathrm{VO}_{2}$ to predict $\mathrm{VO}_{2} \max (20)$. Each subject performed a 6-min submaximal exercise test using the ergometer bike Cardiac Rehab (Monark Ergomedic 818E, Germany). Initially, subjects rested for $15 \mathrm{~min}$ prior to the measurement of resting heart rate. Seat height and handlebars were adjusted to fit the subject prior to the test. According to normative data for submaximal exercise test, young and elderly men who reached the values of $\mathrm{VO}_{2} \mathrm{max}>52 \mathrm{~mL} \cdot \mathrm{kg}^{-1} \cdot \mathrm{min}^{-1}$ and $>5 \mathrm{~mL} \cdot \mathrm{kg}^{-1} \cdot \mathrm{min}^{-1}$, respectively, were classified as active (high active level), and the remaining subjects as inactive (average and low active level).

\section{Blood sampling}

Blood samples were taken from the elbow vein between 8:00 and 9:00 am using S-Monovette-EDTA tubes (Sarstedt, Austria). Within $20 \mathrm{~min}$, they were centrifuged at $1000 \mathrm{~g}$ at $4^{\circ} \mathrm{C}$ for $10 \mathrm{~min}$. Aliquots of plasma were stored at $-80^{\circ} \mathrm{C}$.

\section{Lipid profile and C-reactive protein}

Plasma total cholesterol, high-density lipoproteins (HDL) and low-density lipoproteins (LDL) as well as triglycerides were determined by the professional laboratory company Diagnostyka (Poland, ISO 15189). C-reactive protein (hsCRP) concentration was determined in duplicate by DRG ELISA kit (USA). Detection limit was $0.001 \mathrm{mg} / \mathrm{L}$, and coefficient of variation $(\mathrm{CV})$ for the hsCRP kit was $<3 \%$.

\section{Framingham risk score}

To calculate the subject's overall CVD risk, the conventional CVD risk factors that were measured were applied to the equations based on the Framingham study (22).

\section{Oxidative stress markers}

Total plasma antioxidant status (TAS) and lipid peroxides (LPO) concentrations were determined in duplicate using Oxis Research kits (USA). TAS and LPO detection limits were 0.125 and $0.1 \mathrm{nmol} / \mathrm{mL}$, respectively. Plasma protein carbonyls (PC) concentration, a marker of oxidative protein damage, was determined in duplicate using Alexis immune-assay kit (USA). PC detection limit was $0.1 \mathrm{nmol} / \mathrm{mL}$. Oxidized low-density lipoprotein (oxLDL) was determined in duplicate using EIAab Science kit (China). oxLDL detection limit was $0.312 \mathrm{ng} / \mathrm{mL}$. The intraassay CV for all used kits was between 5 and $8 \%$.

\section{Brain-derived neurotrophic factor}

Plasma BDNF concentration was evaluated in duplicate by the R\&D Systems ELISA kit (USA). BDNF detection limit was $20 \mathrm{pg} / \mathrm{mL}$. The intra-assay CV for the BDNF kit was below $5 \%$.

\section{Statistical analysis}

Statistical analyses were performed using the statistical software Statistica 12 (StatSoft Inc., USA). All data were tested for distribution normality using the ShapiroWilk test. The values of $\mathrm{W}$ for BDNF, health and oxidative stress markers were close to one, therefore statistical significance was assessed using two-way analysis of variance (ANOVA) and post hoc tests (Tukey's HSD). Associations among measured parameters were analyzed using Pearson's linear regression ( $r$ coefficient). Statistical significance was set at $P<0.05$. Results are reported as means $\pm S D$.

\section{Results}

The active and inactive subjects were successfully matched for age, BMl and body composition in both the young and elderly groups. The most significant differences concerning body composition were observed between the young group and the elderly inactive men. FM content was highly correlated with concentrations of hsCRP ( $r=0.709, P<0.001)$, oxLDL $(r=0.497, P<0.01)$ and 10 -year CVD risk $(r=0.659, P<0.001)$. As expected, active subjects had significantly higher $\mathrm{VO}_{2}$ max values (Table 1).

Both young and elderly active men had significantly better lipoprotein profile and reduced hsCRP levels compared to their inactive peers. hsCRP concentration in inactive elderly men was 5-fold higher compared to the young groups. This demonstrates that aging led to a chronic inflammatory state but regular physical activity can counteract this effect (Table 2).

Multiple comparisons revealed that the elderly inactive men had significantly higher oxLDL and lower TAS compared to either the young $(P<0.001)$ active or inactive $(P<0.001)$ groups (Table 2$)$. The percentage of 10 -year CVD risk increased in inactive elderly men by $3 \%$ compared to the active elderly, and by $16 \%$ compared to the young groups. Similarly to the study by Björk et al. (23) and by Narotzki et al. (24), the 10-year CVD risk was significantly correlated with oxLDL level $(r=0.738$, $\mathrm{P}<0.001)$ and antioxidant status $(r=-0.656, \mathrm{P}<0.001)$.

Significant correlations were found between LDL and $\mathrm{HDL}$, and oxidative damage markers such as oxLDL, 
Table 2. Health and oxidative stress markers.

\begin{tabular}{lrcrcr}
\hline & \multicolumn{2}{c}{ Young } & & \multicolumn{2}{c}{ Elderly } \\
\cline { 2 - 3 } \cline { 5 - 6 } & Active $(\mathrm{n}=6)$ & Inactive $(\mathrm{n}=11)$ & & Active $(\mathrm{n}=5)$ & Inactive $(\mathrm{n}=12)$ \\
\hline $\mathrm{TG}(\mathrm{mg} / \mathrm{dL})$ & $72 \pm 19$ & $110 \pm 20^{\#}$ & & $103 \pm 18^{\#}$ & $120 \pm 24$ \\
$\mathrm{TC}(\mathrm{mg} / \mathrm{dL})$ & $151 \pm 23$ & $192 \pm 26^{\#}$ & & $224 \pm 40^{\#}$ & $211 \pm 36$ \\
$\mathrm{LDL}(\mathrm{mg} / \mathrm{dL})$ & $80 \pm 21$ & $110 \pm 21^{\#}$ & & $116 \pm 27^{\#}$ & $147 \pm 32^{*}$ \\
$\mathrm{HDL}(\mathrm{mg} / \mathrm{dL})$ & $68 \pm 13$ & $54 \pm 10^{\#}$ & & $62 \pm 13$ & $49 \pm 12^{*}$ \\
$\mathrm{TC} / \mathrm{HDL}$ & $2.27 \pm 0.60$ & $3.74 \pm 1.10$ & & $3.69 \pm 0.74^{\#}$ & $4.34 \pm 1.16$ \\
$\mathrm{hsCRP}(\mathrm{mg} / \mathrm{dL})$ & $0.07 \pm 0.02$ & $0.15 \pm 0.06^{\#}$ & & $0.38 \pm 0.10^{\#}$ & $0.50 \pm 0.03^{* \&}$ \\
$\mathrm{oxLDL}(\mathrm{ng} / \mathrm{mL})$ & $1.39 \pm 0.76$ & $2.00 \pm 0.74$ & & $2.32 \pm 0.67^{\#}$ & $4.21 \pm 0.87^{* \&}$ \\
$\mathrm{PC}(\mathrm{nmol} / \mathrm{mL})$ & $5.14 \pm 0.76$ & $6.06 \pm 0.65$ & & $7.02 \pm 0.57^{\#}$ & $7.92 \pm 1.62$ \\
LPO $(\mathrm{nmol} / \mathrm{mL})$ & $2.57 \pm 0.55$ & $3.18 \pm 0.36^{\#}$ & & $3.12 \pm 0.22^{\#}$ & $3.70 \pm 0.67$ \\
TAS $(\mathrm{mmol} / \mathrm{L})$ & $3.02 \pm 0.92$ & $2.79 \pm 0.59$ & & $2.51 \pm 0.44$ & $1.22 \pm 0.44^{* \&}$ \\
\hline
\end{tabular}

Data are reported as means \pm SD. TG: triglycerides; TC: total cholesterol; LDL: low-density lipoprotein; HDL: high-density lipoprotein; TC/HDL: atherogenic index; hsCRP: C-reactive protein; oxLDL: oxidized low-density lipoprotein; PC: protein carbonyls; LPO: lipid peroxides; TAS: total antioxidant status. ${ }^{\#} \mathrm{P}<0.05$ vs young active; ${ }^{*} \mathrm{P}<0.05$ vs elderly active; ${ }^{\circledR} \mathrm{P}<0.05$ vs young inactive (ANOVA).

Table 3. Relationships between common cardiovascular disease (CVD) risk factors and oxidative stress markers.

\begin{tabular}{lcccc}
\hline & oxLDL $(\mathrm{ng} / \mathrm{mL})$ & $\mathrm{PC}(\mathrm{nmol} / \mathrm{mL})$ & $\mathrm{LPO}(\mathrm{nmol} / \mathrm{mL})$ & TAS $(\mathrm{mmol} / \mathrm{L})$ \\
\hline LDL $(\mathrm{mg} / \mathrm{dL})$ & 0.684 & 0.689 & 0.501 & -0.625 \\
& $\mathrm{P}<0.001$ & $\mathrm{P}<0.001$ & $\mathrm{P}<0.01$ & $\mathrm{P}<0.001$ \\
HDL $(\mathrm{mg} / \mathrm{dL})$ & -0.544 & -0.533 & -0.393 & 0.472 \\
& $\mathrm{P}<0.01$ & $\mathrm{P}<0.01$ & $\mathrm{P}<0.05$ & $\mathrm{P}<0.01$ \\
10-year CVD risk & 0.737 & 0.621 & 0.473 & -0.656 \\
& $\mathrm{P}<0.001$ & $\mathrm{P}<0.001$ & $\mathrm{P}<0.001$ & $\mathrm{P}<0.001$ \\
\hline
\end{tabular}

Data are reported as Pearson's $r$ coefficient. LDL: low-density lipoprotein; HDL: high-density lipoprotein; oxLDL: oxidized low-density lipoprotein; PC: protein carbonyls; LPO: lipid peroxides; TAS: total antioxidant status.

PC and LPO, as well as antioxidant status (Table 3). TAS was 2-fold lower in inactive than active elderly men. All young men demonstrated sufficient antioxidant status, i.e., $>1.3 \mathrm{mmol} / \mathrm{L}$, whereas the inactive elderly group demonstrated borderline $(<1.3 \mathrm{mmol} / \mathrm{L})$ or low antioxidant status $(<1 \mathrm{mmol} / \mathrm{L})$. There was a positive correlation between $\mathrm{VO}_{2} \mathrm{max}$ and TAS ( $\mathrm{r}=0.589$, $\mathrm{P}<0.001$ ). This clearly shows that aging and inactivity enhance oxidative stress which may relate to impairment of antioxidants and have a detrimental health potential.

The young men had significantly $(P<0.01)$ higher concentrations of BDNF $(1630 \pm 391 \mathrm{pg} / \mathrm{mL})$ than the elderly $(1395 \pm 327 \mathrm{pg} / \mathrm{mL})$. The active subjects, both young and elderly men, had significantly higher BDNF levels compared to their inactive peers (Figure 1). In elderly active men, BDNF concentration was $25 \%$ higher $(\mathrm{P}<0.05)$ than in inactive young men. BDNF concentration was directly correlated with $\mathrm{VO}_{2}$ max level (Figure 2). In addition, we found an inverse relationship between
BDNF and CVD risk factors, such as atherogenic index, hsCRP and oxLDL (Table 4).

\section{Discussion}

Aging is associated with immunosenescence and is accompanied by a chronic inflammatory state which contributes to a metabolic syndrome and cardiovascular consequences. CVD and endothelial dysfunction are characterized by a chronic alteration of inflammatory function. Markers of inflammation and the innate immune response including C-reactive protein and several other pro-inflammatory molecules are linked to the occurrence of myocardial infarction and stroke in healthy elderly populations (25).

HsCRP is an acute phase protein that is considered to be a general inflammatory marker. While the exact biological actions of hsCRP have not been established, its high levels predict risk of mobility/disability and are associated with accelerated decline in physical 

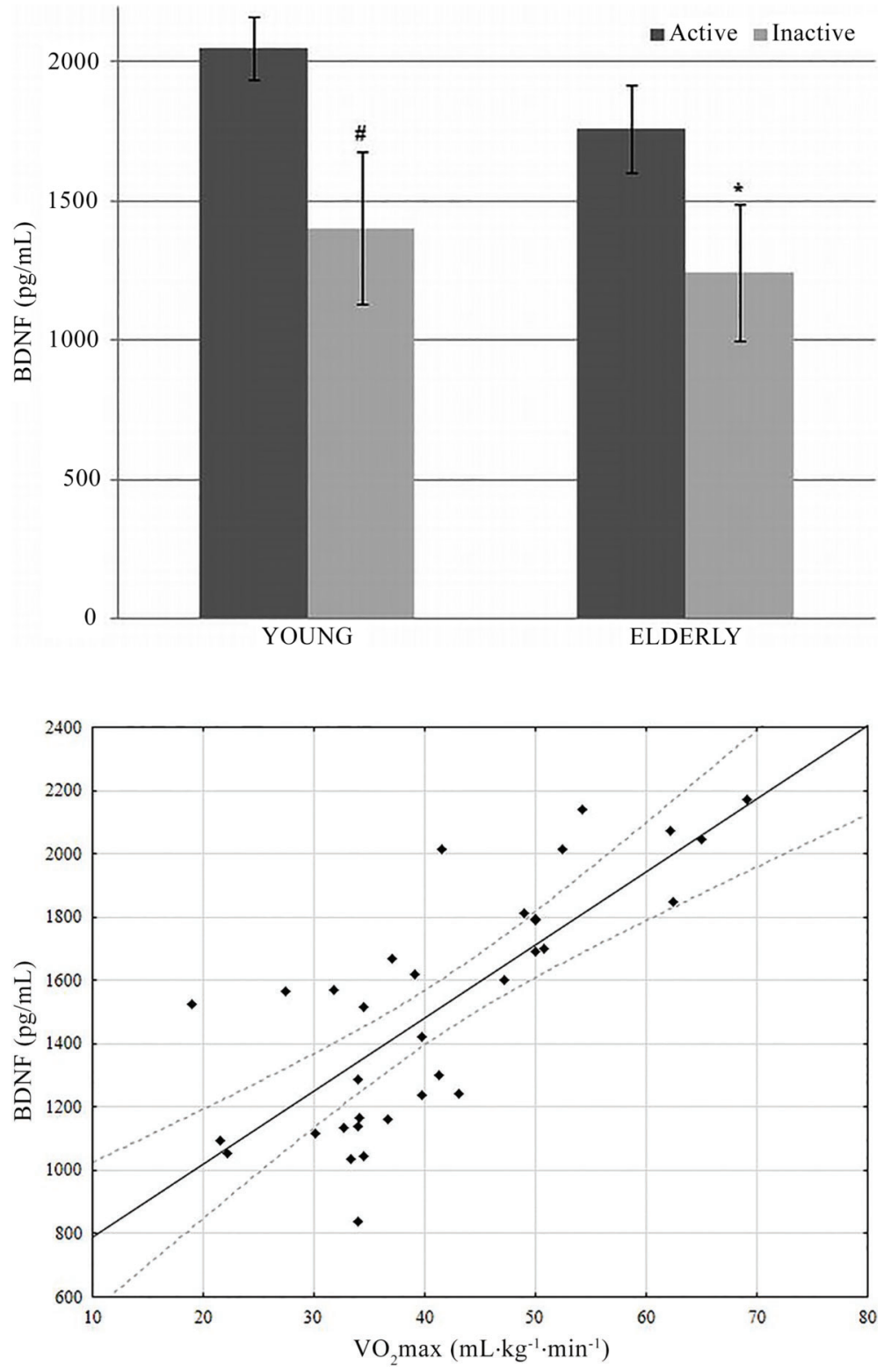

Figure 1. Main effect of age on plasma brainderived neurotrophic factor (BDNF) levels between young $(n=7)$ and elderly $(n=17)$ men. $\# \mathrm{P}<0.05$ vs young active; ${ }^{*} \mathrm{P}<0.05$ vs elderly active (ANOVA).

Figure 2. Correlation results between maximal oxygen consumption $\left(\mathrm{VO}_{2 \max }\right)$ and brain-derived neurotrophic factor (BDNF) concentration. $r=0.765, P<0.001$ (Pearson's linear regression). performance in older adults (26). The observed 5-fold increase in hsCRP concentration in elderly men indicates the presence of low-grade inflammation during aging. Inflammaging is considered a predictor of fragility and is currently accepted as a pathogenic factor in the development of several age-related diseases, such as CVD. Nevertheless, the precise etiology of inflammaging and its potential causal role in adverse health outcomes remain largely unknown. The identification of pathways that control age-related inflammation across multiple systems is, therefore, important in order to understand whether treatments that modulate inflammaging may be beneficial in the elderly population (27).
An increased FM content in elderly men was related to a systemic inflammation state partially promoted by prooxidative processes. The levels of oxLDL, PC and LPO were elevated in elderly men and highly correlated with common CVD risk factors such as LDL, HDL and Framingham score (Table 3). The relationships between oxidative stress markers and CVD risk factors suggest that, at the very least, plasma pro-oxidative molecules may serve as indicators of subclinical atherosclerosis development in clinically healthy men. OxLDL is produced by the oxidation of LDL, migrates into the subendothelial space, and promotes endothelial dysfunction, vascular remodeling, plaque rupture and thrombosis (28). 
Table 4. Relationships between brain-derived neurotrophic factor (BDNF), atherogenic index (TC/HDL), and oxidative stress markers.

\begin{tabular}{llcc}
\hline & TC/HDL & hsCRP $(\mathrm{mg} / \mathrm{L})$ & oxLDL $(\mathrm{ng} / \mathrm{mL})$ \\
\hline BDNF (pg/dL) & -0.473 & -0.466 & -0.560 \\
& $\mathrm{P}<0.01$ & $\mathrm{P}<0.01$ & $\mathrm{P}<0.01$ \\
\hline
\end{tabular}

Data are reported as Pearson's r coefficient. hsCRP: C-reactive protein; oxLDL: oxidized low-density lipoprotein.

Many pathological changes associated with aging are explained by the irreversible accumulation of pro-oxidative molecules (29). Therefore, one would expect older individuals to have an impairment in antioxidant defense. We observed significantly decreased plasma TAS in elderly men compared to the young subjects. Although acute exercise results in elevated oxidative stress, some recent studies have found that both low and high physical fitness levels help maintain better antioxidant potential in older adults $(1,30)$. Our study demonstrated that active individuals had higher TAS as well as lower oxLDL, PC and LPO than their sedentary peers. This confirms previous results of reduced oxidative damage following an exercise intervention (23). Also, our positive correlation between $\mathrm{VO}_{2}$ max and TAS further supports the hypothesis that elevated physical activity enhances antioxidant defense.

Low-grade inflammation and oxidative stress are common during aging and seem to be linked to degenerative diseases (25-27). Regular physical exercise can help to reduce an inflammatory state and to improve tissue function $(1,3)$. BDNF is considered one of the most plausible factors involved in the health benefits associated with physical activity $(3,4,14)$. In the present study, we found that high levels of cardiorespiratory fitness (estimated by the Åstrand-Rhyming test) was related with increased circulating BDNF concentration in both young and elderly men. Individuals with higher $\mathrm{VO}_{2}$ max demonstrated elevated plasma BDNF level. The majority of previous studies suggest an inverse association between BDNF and habitual physical activity or cardiorespiratory fitness $(16,31,32)$, which seems to be in conflict with the results from experimental studies $(18,19,33,34)$. According to Huang et al. (14), discrepancy in results may be caused by various sample sizes, ranging from 8 to 955 , and different measures of physical activity such as $\mathrm{VO}_{2} \mathrm{max}$, lifestyle questionnaire and energy expenditure. Therefore, it is difficult to observe the

\section{References}

1. Radak Z, Chung HY, Goto S. Exercise and hormesis: oxidative stress-related adaptation for successful aging. Biogerontology 2005; 6: 71-75, doi: 10.1007/s10522-004-7386-7.

2. Mattson MP, Wan R. Beneficial effects of intermittent fasting and caloric restriction on the cardiovascular and unambiguous relationship between BDNF and physical activity due to limitations, such as selected study populations, subjective measures of physical activity, and uncontrolled confounding factors (14).

The biological mechanisms underlying the relationship between peripheral BDNF and habitual physical activity is still unclear, but several potential explanations are suggested. Firstly, the brain is a major source for increased plasma BDNF in physically active individuals (9). Warnn et al. (35) reported that the FNDC5 protein is released during exercise from skeletal muscles, inducing BDNF from hippocampus. Secondly, most of the peripheral BDNF is stored in platelets which might release BDNF in response to exercise at the site of injury to promote vascular repair (36). Furthermore, immune cells also release BDNF, which could sustain tissue repair in inflamed places (37). According to a recent study, BDNF may have a protective role in counteracting the inflammatory effects of hsCRP (11).

This is the first study to demonstrate that high plasma BDNF levels associated with physical activity may have an impact on CVD risk factors such as atherogenic index, oxLDL and hsCRP (Table 4). Recently, Noren Hooten et al. (11) observed that BDNF can reduce hsCRP levels and inhibit CRP-induced oxidative DNA damage in African-American women. Currently, BDNF is identified as a novel contraction-induced protein that may contribute to the multiple health benefits associated with physical exercise. In contrast, inactivity and low circulating BDNF levels are associated with many chronic disorders such as obesity, type 2 diabetes, cardiovascular diseases, depression, dementia and cognitive impairment (3). Matthews et al. (8) even suggested the possibility of using BDNF analogues as a possible therapy to treat metabolic diseases.

Our findings demonstrate that high levels of cardiorespiratory fitness reflected in $\mathrm{VO}_{2}$ max were associated with higher levels of circulating BDNF, which in turn were related to common CVD risk factors and oxidative damage markers in young and elderly men. However, it is too early to draw a clear conclusion on a clinically relevant relationship between BDNF and habitual physical activity due to the small sample size.

\section{Acknowledgments}

This study was supported by statutory funds from the University of Zielona Gora and the University School of Physical Education Wroclaw, Poland.

cerebrovascular systems. J Nutr Biochem 2005; 16: 129137, doi: 10.1016/j.jnutbio.2004.12.007.

3. Pedersen BK, Pedersen M, Krabbe KS, Bruunsgaard H, Matthews VB, Febbraio MA. Role of exercise-induced brain-derived neurotrophic factor production in the regulation 
of energy homeostasis in mammals. Exp Physiol 2009; 94: 1153-1160, doi: 10.1113/expphysiol.2009.048561.

4. Adlard PA, Cotman CW. Voluntary exercise protects against stress-induced decreases in brain-derived neurotrophic factor protein expression. Neuroscience 2004; 124: 985-992, doi: 10.1016/j.neuroscience.2003.12.039.

5. Hunsberger J, Austin DR, Henter ID, Chen G. The neurotrophic and neuroprotective effects of psychotropic agents. Dialogues Clin Neurosci 2009; 11: 333-348.

6. Seifert T, Brassard P, Wissenberg M, Rasmussen P, Nordby P, Stallknecht B, et al. Endurance training enhances BDNF release from the human brain. Am J Physiol Regul Integr Comp Physiol 2010; 298: R372-R377, doi: 10.1152/ajpregu.00525.2009.

7. Kermani P, Rafii D, Jin DK, Whitlock P, Schaffer W, Chiang A, et al. Neurotrophins promote revascularization by local recruitment of TrkB + endothelial cells and systemic mobilization of hematopoietic progenitors. J Clin Invest 2005; 115: 653-663, doi: $10.1172 / \mathrm{JCl} 200522655$.

8. Matthews VB, Astrom MB, Chan MH, Bruce CR, Krabbe KS, Prelovsek $O$, et al. Brain-derived neurotrophic factor is produced by skeletal muscle cells in response to contraction and enhances fat oxidation via activation of AMP-activated protein kinase. Diabetologia 2009; 52: 1409-1418, doi: 10.1007/s00125-009-1364-1.

9. Rasmussen $P$, Brassard $P$, Adser $H$, Pedersen MV, Leick L, Hart $E$, et al. Evidence for a release of brain-derived neurotrophic factor from the brain during exercise. Exp Physiol 2009; 94: 1062-1069, doi: 10.1113/expphysiol. 2009.048512.

10. Lommatzsch M, Zingler D, Schuhbaeck K, Schloetcke K, Zingler $C$, Schuff-Werner $P$, et al. The impact of age, weight and gender on BDNF levels in human platelets and plasma. Neurobiol Aging 2005; 26: 115-123, doi: 10.1016/ j.neurobiolaging.2004.03.002.

11. Noren Hooten N, Ejiogu N, Zonderman AB, Evans MK. Protective effects of BDNF against $\mathrm{C}$-reactive proteininduced inflammation in women. Mediators Inflamm 2015; 2015: 516783;.., doi: 10.1155/2015/516783.

12. Coelho FG, Gobbi S, Andreatto CA, Corazza DI, Pedroso RV, Santos-Galduroz RF. Physical exercise modulates peripheral levels of brain-derived neurotrophic factor (BDNF): a systematic review of experimental studies in the elderly. Arch Gerontol Geriatr 2013; 56: 10-15, doi: 10.1016/j.archger. 2012.06.003.

13. Leckie RL, Oberlin LE, Voss MW, Prakash RS, Szabo-Reed A, Chaddock-Heyman L, et al. BDNF mediates improvements in executive function following a 1-year exercise intervention. Front Hum Neurosci 2014; 8: 985, doi: 10.3389/fnhum. 2014.00985., doi: 10.3389/fnhum.2014.00985.

14. Huang T, Larsen KT, Ried-Larsen M, Moller NC, Andersen LB. The effects of physical activity and exercise on brain-derived neurotrophic factor in healthy humans: A review. Scand J Med Sci Sports 2014; 24: 1-10, doi: 10.1111/sms.12069.

15. Knaepen K, Goekint M, Heyman EM, Meeusen R. Neuroplasticity - exercise-induced response of peripheral brain-derived neurotrophic factor: a systematic review of experimental studies in human subjects. Sports Med 2010; 40: 765-801, doi: 10.2165/11534530-000000000-00000.

16. Currie J, Ramsbottom R, Ludlow $H$, Nevill A, Gilder M. Cardio-respiratory fitness, habitual physical activity and serum brain derived neurotrophic factor (BDNF) in men and women. Neurosci Lett 2009; 451: 152-155, doi: 10.1016/j.neulet.2008.12.043.

17. Babaei P, Damirchi A, Mehdipoor M, Tehrani BS. Long term habitual exercise is associated with lower resting level of serum BDNF. Neurosci Lett 2014; 566: 304-308, doi: 10.1016/j.neulet.2014.02.011.

18. Whiteman AS, Young DE, He X, Chen TC, Wagenaar RC, Stern CE, et al. Interaction between serum BDNF and aerobic fitness predicts recognition memory in healthy young adults. Behav Brain Res 2014; 259: 302-312, doi: 10.1016/j.bbr.2013.11.023.

19. Erickson KI, Voss MW, Prakash RS, Basak C, Szabo A, Chaddock $L$, et al. Exercise training increases size of hippocampus and improves memory. Proc Natl Acad Sci U S A 2011; 108: 3017-3022, doi: 10.1073/pnas.1015950108.

20. Astrand PO. Human physical fitness with special reference to sex and age. Physiol Rev 1956; 36: 307-335.

21. Durstine JL, Moore GE. ACSM's exercise management for persons with chronic diseases and disabilities. 2nd edn. Champaign: Human Kinetics; 2003.

22. Wilson $P W$, D'Agostino RB, Levy $D$, Belanger $A M$, Silbershatz $\mathrm{H}$, Kannel WB. Prediction of coronary heart disease using risk factor categories. Circulation 1998; 97 : 1837-1847, doi: 10.1161/01.CIR.97.18.1837.

23. Björk L, Jenkins NT, Witkowski S, Hagberg JM. Nitro-oxidative stress biomarkers in active and inactive men. Int $J$ Sports Med 2012; 33: 279-284, doi: 10.1055/s-0032-1301891.

24. Narotzki B, Reznick AZ, Mitki T, Aizenbud D, Levy Y. Enhanced cardiovascular risk and altered oxidative status in elders with moderate excessive body fat. Rejuvenation Res 2014; 17: 334-340, doi: 10.1089/rej.2013.1540.

25. Guarner V, Rubio-Ruiz ME. Low-grade systemic inflammation connects aging, metabolic syndrome and cardiovascular disease. Interdiscip Top Gerontol 2015; 40: 99-106, doi: $10.1159 / 000364934$.

26. Verghese J, Holtzer R, Lipton RB, Wang C. High-sensitivity C-reactive protein and mobility disability in older adults. Age Ageing 2012; 41: 541-545, doi: 10.1093/ageing/ afs038.

27. Franceschi C, Campisi J. Chronic inflammation (inflammaging) and its potential contribution to age-associated diseases. J Gerontol A Biol Sci Med Sci 2014; 69 (Suppl 1): S4-S9, doi: 10.1093/gerona/glu057.

28. Stocker R, Keaney JF Jr. Role of oxidative modifications in atherosclerosis. Physiol Rev 2004; 84: 1381-1478, doi: 10.1152/physrev.00047.2003.

29. Sohal RS, Weindruch R. Oxidative stress, caloric restriction, and aging. Science 1996; 273: 59-63, doi: 10.1126/ science.273.5271.59.

30. Ceci R, Beltran Valls MR, Duranti G, Dimauro I, Quaranta F, Pittaluga $M$, et al. Oxidative stress responses to a graded maximal exercise test in older adults following explosive-type resistance training. Redox Biol 2014; 2: 65-72, doi: 10.1016/j.redox.2013.12.004.

31. Joung SH, Kim J, Davis JM, Blair SN, Cho HC. Association among basal serum BDNF, cardiorespiratory fitness and cardiovascular disease risk factors in untrained healthy Korean men. Eur J Appl Physio 2011; 111: 303-311, doi: 10.1007/s00421-010-1658-5.

32. Nofuji $Y$, Suwa $M$, Moriyama $Y$, Nakano $H$, Ichimiya $A$, Nishichi $R$, et al. Decreased serum brain-derived 
neurotrophic factor in trained men. Neurosci Lett 2008; 437: 29-32, doi: 10.1016/j.neulet.2008.03.057.

33. Zoladz JA, Pilc A, Majerczak J, Grandys M, Zapart-Bukowska $\mathrm{J}$, Duda K. Endurance training increases plasma brainderived neurotrophic factor concentration in young healthy men. J Physiol Pharmacol 2008; 59 (Suppl 7): 119-132.

34. Correia PR, Scorza FA, Gomes da SS, Pansani A, Toscano-Silva M, de Almeida AC, et al. Increased basal plasma brain-derived neurotrophic factor levels in sprint runners. Neurosci Bull 2011; 27: 325-329, doi: 10.1007/ s12264-011-1531-5.
35. Warnn CD, White JP. FNDC5 a muscle protein induces BDNF release from hippocampus. Cell Metab 2013; 5: 649-659.

36. Yamamoto $H$, Gurnay ME. Human platelets contain brain-derived neurotrophic factor. J Neurosci 1990; 10: 3469-3478.

37. Colombo E, Bedogni F, Lorenzetti I, Landsberger N, Previtali SC, Farina C. Autocrine and immune cell-derived BDNF in human skeletal muscle: implications for myogenesis and tissue regeneration. J Pathol 2013; 231: 190-198, doi: 10.1002/path.4228. 